\title{
Testing and Predicting Volatility Spillover-A Multivariate GJR-GARCH Approach
}

\author{
Hira Aftab ${ }^{1,2 *}$, Rabiul Alam Beg1, Sizhong Sun ${ }^{1}$, Zhangyue Zhou1 \\ ${ }^{1}$ College of Business, Law and Governance, James Cook University, Townsville, Australia \\ ${ }^{2}$ Institute of Business \& Information Technology, University of the Punjab, Lahore, Pakistan \\ Email: `hira.aftab@my.jcu.edu.au, rabiul.beg@jcu.edu.au, sizhongun@jcu.edu.au, Zhangyue.hou@jcu.edu
}

How to cite this paper: Aftab, H., Beg, R.A., Sun, S.Z. and Zhou, Z.Y. (2019) Testing and Predicting Volatility Spillover-A Multivariate GJR-GARCH Approach. Theoretical Economics Letters, 9, 83-99. https://doi.org/10.4236/tel.2019.91008

Received: October 24, 2018

Accepted: January 26, 2019

Published: January 29, 2019

Copyright $\odot 2019$ by author(s) and Scientific Research Publishing Inc. This work is licensed under the Creative Commons Attribution International License (CC BY 4.0).

http://creativecommons.org/licenses/by/4.0/

(c) (i) Open Access

\begin{abstract}
This paper proposes a multivariate VAR-BEKK-GJR-GARCH volatility model to assess the dynamic interdependence among stock, bond and money market returns and volatility of returns. The proposed model allows for market interaction which provides useful information for pricing securities, measuring value-at-risk ( $\mathrm{VaR})$, and asset allocation and diversification, assisting financial regulators for policy implementation. The model is estimated by the maximum likelihood method with Student-t innovation density. The asymptotic chi-square tests for volatility spillovers and leverage effects are constructed and provide predictions of volatility and time-varying correlations of returns. Application of the proposed model to the Australia's domestic stock, bond, and money markets reveals that the domestic financial markets are interdependent and volatility is predictable. In general, volatility spillovers from stock market to bond and to money markets due to common news. The empirical findings of this paper quantify the association among the security markets which can be utilized for improving agents' decision-making strategies for risk management, portfolio selection and diversification.
\end{abstract}

\section{Keywords}

Asymmetric News, Diversification, Spillovers, Multivariate-t, Chi-Square Test

\section{Introduction}

Security traders in the financial markets make their "buy" and "sell" decisions based on the information available in the financial markets. The amount of risk associated with a series of returns, however, depends on the arrival of the so-called "good" and "bad" news that continuously spreads throughout the fi- 
nancial markets in every moment of time. Since "news" is not directly observable, returns are stochastic and volatile. An interesting feature of asset price is that "bad" news seems to have a more pronounced effect on volatility than does the "good" news. This asymmetric "news" is associated with the innovation distribution of losses and gains in the financial markets, which plays a vital role in determining the leverage effect on asset volatility. Black [1] finds that the leverage effect is caused by the fact that negative returns have greater influences on future volatility than do the positive returns. To understand the dynamics of simultaneous presence of "news" and "leverage" effects on volatility, we are required to develop forms of the expected returns and volatility of return processes of a financial time series. There are three main ways of modelling financial volatility, namely, implied volatility, realized volatility, and conditional volatility. In this paper we use the conditional volatility approach.

In developing dynamic volatility models, there are two strands of modelling conditional volatility - the univariate and multivariate volatility modelling respectively. Engle [2] first introduced univariate autoregressive conditional heteroskedasticity $(\mathrm{ARCH})$ model for measuring and predicting asset return volatility. This model is useful because it captures some stylized facts such as volatility clustering and thick-tail distribution of return series. Bollerslev [3] extended the ARCH model which allowed for the effect of past volatility in the expanded ARCH model. This extension is widely known as the generalized ARCH (or GARCH) model. Although useful, the basic ARCH/GARCH models are incapable to capturing leverage effects. Leverage effect is the tendency for volatility to decline when returns rise and to rise when returns fall. Black [1] first discovered the leverage effect that existed in the financial data and confirmed by French, Schwert, and Stambaugh (1987). Various types of volatility models, within the univariate framework, have been developed in the literature to address both the theory and empirical issues of the model, namely, the news asymmetry, volatility clustering, thick-tail, non-normality, and risk premium in the financial returns. For example, Nelson [4] develops an Exponential GARCH (EGARCH), Engle and Ng [5] provide nonparametric tests for asymmetry between news and volatility, and Glosten et al. [6] propose asymmetric GARCH model. The asymmetric GARCH of Glosten et al. [6] is generally known as threshold GARCH (TGARCH or GJR-GARCH) model. In the risk-return framework there was another development of the univariate ARCH/GARCH model, in which the first moment of a series is allowed to include the information generated by the second moment of the returns series. This specification is capable to deal with investor/agent's demand for compensation for holding risky assets. This extension is widely known as ARCH-in-Mean (or ARCH-M) model developed by Engle et al. [7]. Further extension such as GARCH-M, GJR-GARCH can be found elsewhere.

The first two moments respectively called mean and variance of return series have been investigated extensively in the univariate finance literature to understand the trading dynamics of risk and returns in the financial asset markets, for example Bollerslev [8] and Bera [9], among others. These articles use various 
modeling issues e.g. functional form and dependence. Joint estimation of the univariate mean-variance models reported elsewhere uses t-distribution or generalized error distributions (GED) as one might not want to perform a maximum likelihood estimation using normal distribution, because the normality assumption of unconditional volatility of innovation might not hold [10].

The Second strand of volatility modelling has been emerged from modelling volatilities of returns within the multivariate framework. Within this framework the shocks to volatility from one market is allowed to affect both the risk and return of the other markets. The dynamic dependence of multivariate financial assets provides rich sources of volatility transmission that helps the investors to play active role in financial transactions. Specifically, the multivariate extension to univariate GJR-GARCH (or TGARCH) allows volatility spillovers and leverage effects across markets jointly. Directional causality between assets can be established among the securities by statistical testing. The multivariate extension to univariate model was first introduced by Engle and Granger [7] in the ARCH context, and Bollerslev, Engle and Wooldridge [8] in the GARCH context. This multivariate GARCH is known as VEC model because of its structure. Further development of the multivariate volatility model is the Baba-Engle-Kraft-Kroner (BEKK) model [11] [12]. This model allows for dynamic dependence between the volatility series. This model is statistically sound but the interpretation of the model parameters is not straight forward.

In this paper we take the challenge of fitting our proposed multivariate VAR-BEKK-GJR-GARCH (or, VAR-BEKK-GJR-MGARCH) volatility model and investigate the dynamic interdependence among assets. This model is different from Ling and McAleer [13] in that our model does not restrict the volatility correlations and uses $t$ (with unknown shape parameter) to comply with the data coherent innovation distribution. Our model is more general than the Engle-Kroner [12] BEKK formulation, in that our model captures the multivariate leverage effect and volatility spillovers jointly. This paper is organized as follows. In Section 2, model and methodology is discussed. Section 3 describes the sources and statistical properties of the data. Real application of the proposed model is reported in Section 4. Finally, Section 5 concludes the paper with future research directions.

\section{Econometric Methodology}

To apprehend the dynamic interdependence of asset returns and volatility spillovers, we combine Engle and Kroner [12] BEKK with GJR-MGARCH for modelling volatility dynamics. The dynamics of return is assumed to be generated by a vector autoregressive process. Our model combines vector autoregressive conditional mean with dynamic BEKK-GJR-MGARCH second moment of multivariate time series. This model allows for the stylized facts of financial series such as, asymmetry, excess kurtosis, volatility clustering and persistence. In the same sprit as Engle-Kroner [12], our model also guarantees that the covariance matrix 
of volatility is positive definite. This property is a requirement of a statistical model. The model is estimated by the maximum likelihood method using multivariate t-innovation density. The maximum likelihood estimates (MLE) of the model parameters are consistent and asymptotically normally distributed. Further the dynamic correlations between volatilities can be computable and predictable under this specification. Real data of the Australia's domestic asset markets are used to demonstrate the performance of the proposed model.

\subsection{The Multivariate BEKK-GJR-GARCH Volatility Model}

Let $r_{r}=\left(r_{1 t}, r_{2 t}, \cdots, r_{N t}\right)^{\prime}$ be a vector of returns of $N$ number of assets at time index $t(t=1,2,3, \cdots, T)$. The set of information available at time $\mathrm{t}$ is denoted by $\mathfrak{I}_{t-1}$. We assume that the dynamic multivariate security returns $r_{t}$ can be adequately represented by a vector autoregression of order $p$ conditional on the information set $\mathfrak{J}_{t-i}$ as

$$
r_{t} \mid \mathfrak{J}_{t-1}=\Phi_{0}+\sum_{l=1}^{p} \Phi(l) r_{t-l}+\varepsilon_{t}
$$

where, $E\left(r_{t} \mid \mathfrak{J}_{t-1}\right)=\Phi_{0}+\sum_{l=1}^{p} \Phi(l) r_{t-l}=\mu_{t}$, say, and $\Phi(l)=\left(\Phi_{i j}(l)\right)$ is the $N \times N$ coefficient matrix of the lagged variables. The $N \times 1$ intercept vector is denoted by $\Phi_{0}$ and $\varepsilon_{t} \mid \mathfrak{I}_{t-1}=H_{t}^{0.5} e_{t}$, where $e_{t}=\left(e_{1 t}, e_{2 t}, \cdots, e_{N t}\right)^{\prime}$ is the independent and identically distributed (iid) random vectors of order $N \times 1$ with $E e_{t}=0$ and $E e_{t} e_{t}^{\prime}=I_{N}$, where $I_{n}$ is an Identity matrix. The symmetric matrix $H_{t}$ is of order $N \times N$ represents the conditional variance-covariance matrix of innovations defines as follows.

$$
H_{t}=E\left(\varepsilon_{t} \varepsilon_{t}^{\prime} \mid \mathfrak{I}_{t-1}\right)=E\left(r_{t}-E\left(r_{t}\right)\right)\left(r_{t}-E\left(r_{t}\right)\right)^{\prime} \mid \mathfrak{I}_{t-1}
$$

Model (1) with (2) can be written more compactly as $r_{t} \mid \mathfrak{I}_{t-1} \sim D\left(\mu_{t}, H_{t}\right)$, where $D(.,$.$) is some specified probability distribution. Or, equivalently as$ $\varepsilon_{t} \mid \mathfrak{I}_{t-1} \sim D\left(0, H_{t}\right)$. Various parameterizations for $H_{t}$ have been proposed in the literature, for example, Bollerslev et al. [8], Engle [14] and Tsui [15] among others.

To allow for asymmetric transmission of "good" and "bad" "news" information from one asset to another and /or from one market to another, we define a multivariate indicator vector along the lines with Glosten et al. [6] and Zakoian [16] as follows.

$$
d_{i t-1}=\left\{\begin{array}{lll}
1 & \text { if } \varepsilon_{i t-1}<0 & \text { ("bad" news) } \\
0 & \text { if } \varepsilon_{i t-1} \geq 0 \quad \text { ("good" news) }
\end{array}\right.
$$

We define the variable $\eta_{i t-1}=d_{i t} \varepsilon_{i t-1}^{2}$ to introduce the leverage effects on volatility. Allowing both the news and leverage effects on volatility, we specify (2) as follows.

$$
H_{t}=C^{\prime} C+A^{\prime} \varepsilon_{t-1} \varepsilon_{t-1}^{\prime} A+B^{\prime} H_{t-1} B+\Gamma^{\prime} \eta_{t-1} \eta_{t-1}^{\prime} \Gamma
$$

Combining the leverage effects within BEKK volatility model, we have the 
following VAR-BEKK-GJR-MGARCH (or VAR-BEKK-TMGARCH) model.

$$
\begin{aligned}
& \text { Return: } r_{t}\left|\mathfrak{J}_{t-1}=\Phi_{0}+\sum_{l=1}^{p} \Phi(l) r_{t-l}+\varepsilon_{t}, \varepsilon_{t}\right| \mathfrak{I}_{t-1} \sim D\left(0, H_{t}\right) \\
& \text { Volatility: } H_{t} \mid \mathfrak{\Im}_{t-1}=C C^{\prime}+A \varepsilon_{t-1} \varepsilon_{t-1}^{\prime} A^{\prime}+B H_{t-1} B^{\prime}+\Gamma \eta_{t-1} \Gamma^{\prime}
\end{aligned}
$$

where, $\Gamma=\left(\gamma_{i j}\right)$ is an $N \times N$ matrix of parameters associated with the individual and cross asset leverage effects. The parameters $\Phi_{0}$ and $\Phi(l)$ is the coefficient matrix of the autoregression of lag order 1 . The matrix $C$ is a $N \times N$ lower triangular matrix such that $C C^{\prime}$ is symmetric and positive definite containing the intercept parameters of the volatility model. The matrices $A=\left(\alpha_{i j}\right)$ and $B=\left(\beta_{i j}\right), i, j=1,2,3, \cdots, N$, are both $N \times N$ matrices of short-run and long-run parameters, respectively and the innovation $\varepsilon_{t}$ is as defined above. The model (2') provides both quality and quantity effects on volatility jointly. If $\Gamma$ is a zero matrix then (2') boils down to Engle-Kroner [12] BEKK-MGARCH model.

\subsection{Estimation of the VAR-BEKK-GJR-MGARCH Model}

In order to estimate the parameters of the model (1') and (2') jointly, we assume that the innovation vector follows a multivariate $t$-distribution with unknown (but equal) degrees of freedom. The advantage of using the $t$-distribution is that it nests the normal distribution as a limiting case. The t-distribution with small number of degrees of freedom captures skewness and fat-tailed property of return series. Therefore, a data coherent assumption of $t$-distribution of innovation is meaningful and useful for modelling volatility clustering and non-normality of the financial asset returns. The multivariate $\mathrm{t}$-distribution with $\mathrm{T}$ observations has the following log-likelihood function.

$$
\ln L=\text { constant }-\frac{N T}{2} \ln \left(\left|H_{t}\right|\right)-\left(\frac{v+N}{2}\right) \sum_{t} \ln \left(1+\frac{\left(r_{t}-\mu_{t}\right) H_{t}^{-1}\left(y_{t}-\mu_{t}\right)^{\prime}}{v}\right)
$$

where $\mu_{t}=\Phi_{0}+\sum^{p} \Phi(l) r_{t-j}$ is the mean vector of returns (see Equation (1)), $\left|H_{t}\right|$ is the determinant of the VCV matrix of the innovation vector, $\ln ($.$) is$ the natural logarithm of the argument and, $v$ is the unknown shape parameter and $\ln L$ is the $\log$-likelihood function of the parameters given the data. Maximum likelihood method is applied to estimate the parameters of the VAR-BEKK-GJR-MGARCH model under the assumption of multivariate $\mathrm{t}$-distribution using FBGLS optimization routine in RATS. The maximum likelihood estimates (MLE) are consistent and asymptotically normally distributed. This property is useful for developing statistical tests on the parameters.

\subsection{Tests for Spillovers and Leverage Effects}

Refer to the multivariate volatility model of Section 2.1, the following hypotheses are of interest to test for return and volatility spillovers and, leverage effects across assets. Considering three assets portfolio, the following hypotheses can be 
tested by applying Chi-square tests.

\subsubsection{Return Spillovers from Asset $j$ and $k$ to Asset $i(i \neq j \neq k=1,2,3)$}

1) Return spillovers from bond and Tbill to stock

$H_{0}: \phi_{12}=\phi_{13}=0$ against $H_{1}: \phi_{12} \neq \phi_{13} \neq 0$

2) Return spillovers from stock and Tbill to bond

$H_{0}: \phi_{21}=\phi_{23}=0$ against $H_{0}: \phi_{21} \neq \phi_{23} \neq 0$

3) Return spillovers from stock and bond to Tbill

$H_{0}: \phi_{31}=\phi_{32}=0$ against $H_{1}: \phi_{31} \neq \phi_{32} \neq 0$

\subsubsection{Volatility Spillovers from Asset $j$ and $k$ to Asset $i$}

$(i \neq j \neq k=$ Stock, Bond,Tbill )

1) Volatility spillovers from bond and Tbill to stock

$H_{0}: \alpha_{12}=\alpha_{13}=\beta_{12}=\beta_{13}=0$ against $H_{1}: \alpha_{12} \neq \alpha_{13} \neq \beta_{12} \neq \beta_{13} \neq 0$

2) Volatility spillovers from stock and Tbill to bond

$H_{0}: \alpha_{21}=\alpha_{23}=\beta_{21}=\beta_{23}=0$ against $H_{1}: \alpha_{21} \neq \alpha_{23} \neq \beta_{21} \neq \beta_{23} \neq 0$

3) Volatility spillovers from stock and bond to Tbill

$H_{0}: \alpha_{31}=\alpha_{32}=\beta_{31}=\beta_{32}=0$ against $H_{1}: \alpha_{31} \neq \alpha_{32} \neq \beta_{31} \neq \beta_{32} \neq 0$

\subsubsection{Leverage Effects on Asset Returns Volatility}

We perform the following hypothesis tests for the presence of leverage effects of own shock and shocks due to the other assets on volatility by testing the leverage parameters $\gamma_{i j}(i=1,2,3 ; j=1,2,3)$ representing the simultaneous occurrence of the asymmetric news and leverage in model (4).

1) Leverage effect for stock volatility

$H_{0}: \gamma_{11}=\gamma_{12}=\gamma_{13}=0$ against $H_{1}: \gamma_{11} \neq \gamma_{12} \neq \gamma_{13} \neq 0$

2) Leverage effect for bond volatility

$H_{0}: \gamma_{21}=\gamma_{22}=\gamma_{23}=0$ against $H_{1}: \gamma_{21} \neq \gamma_{22} \neq \gamma_{23} \neq 0$

3) Leverage effect for Tbill volatility

$H_{0}: \gamma_{31}=\gamma_{32}=\gamma_{33}=0$ against $H_{1}: \gamma_{31} \neq \gamma_{32} \neq \gamma_{33} \neq 0$

The above hypotheses tests of Section 2.3 were performed by employing Chi-square tests in RATS programing. We have reported the Chi-square test results in the empirical section 4 .

\section{Data and Preliminary Results}

Historical data on stock, bond, and Tbill of Australia's domestic market from 4 April 2006 to 20 June 2016, for a total 883 observations are used for analysis. The data was retrieved from Bloomberg database. The daily returns, in percentages, for stock (all ordinaries), bond (5-year maturity rate), and Tbill (90 day bank accepted bank accepted bill are) are constructed by the following growth rate form.

$$
r_{i t}=100 \times \ln \left(\frac{p_{i t}}{p_{i t-1}}\right), \quad i=1,2, \cdots, N ; \quad t=1,2, \cdots, T
$$

The variable $p_{i t}$ denote the nominal price of the $i$-th asset at time $t$ and the 
variable $r_{i t}$ is the percentage log returns (or the growth rate) of the $i$-th asset at time $t, p_{i t-1}$ is the one-period lag of $p_{i t}$, and $\ln ($.$) is the natural logarithm of$ the argument. $N$ is the number of asset and $T$ is the time index.

\section{Data Property and Preliminary Results}

In this section we provide graphical means to explore the data properties. First we plot the return series and the squared return series. Then we provide the serial correlations and cross correlation of the variables to determine the data dependencies by employing ACF and PACF graphs and Ljung-Box [17] cross-correlation test. We use RATS package for empirical computation of this paper.

Figure 1 shows the time plots of daily log returns, in percentage, of (a) Stock, (b) Bond, and (c) Tbill. The volatility seems to be larger during June 2008-December 2008 and August 2011-February 2012 for stock returns; October 2008-April 2009, August 2011-December 2011, March 2012-November 2013, and March 2015-December 2015 for bond, and occasionally around December 2009 and July 2011-August 2011 for Tbill. Time plot of daily log returns highlighted that Bond market is affected the most by the global financial crisis (GFC) while Tbill is least affected as Tbill is for short term and 5 year bond market is for long term. Therefore, the three Australian financial markets are affected simultaneously with some variation.

Figure 2 shows some dependence in the individual asset returns with high peaks of volatility. This is further confirmed by the Ljung-Box test [17] reported in summary (Table 1). The jumps are particularly associated with global financial crisis (GFC) periods for all of the series as the jumps are around 2008-2009 and 2011-2012 and 2015 for stock; 2008-2009, 2011-2012, 2014-2015 for bond; and occasionally around 2009 and 2011-2012 for Tbill. The spikes and the LB-Q statistics on the squared series suggests that the percentage changes of the series have some ARCH effects.

Table 1 provides various statistics to judge the data properties. In particular, all of the return series significantly skewed and are heavy-tailed distribution. The later property reveals that the series exhibits volatility clustering. This shows that the rare tail-events have longer effects. The mean of the Stock and Tbill are insignificant while the average bond return is significant at the $5 \%$ level. Serial correlation up to 20 lags for stock and Tbill are insignificant but bond returns are serially dependent. The squares series, however exhibits serial dependence in the second moment for all of the series. Both the Tsay [18] and McLeod and Li [19] tests supports for nonlinearity in all of the series. Existence of conditional volatility in all series is supported by the Engle [2] ARCH test. Further, the normality of all of the series is rejected by the Jarque-Bera [20] test. We have also applied Ljung-Box test [16] for cross-correlation to all of the series the series (not reported, can be obtained from the author), some significance negative positive cross-correlation exists among the variables at different lags. The series are further tested for unit root nonstationay by augmented Fuller [21], Perron, and 
KPSS tests [22]. The test results as provided below.

All of the tests results indicate that the series are not unit root processes. The test results of Table 1 and Table 2 reveal that we jointly model the observed facts of the first and second moments of the data generating process to investigate dependence structure of the variables within the multivariate framework, which is discussed below.

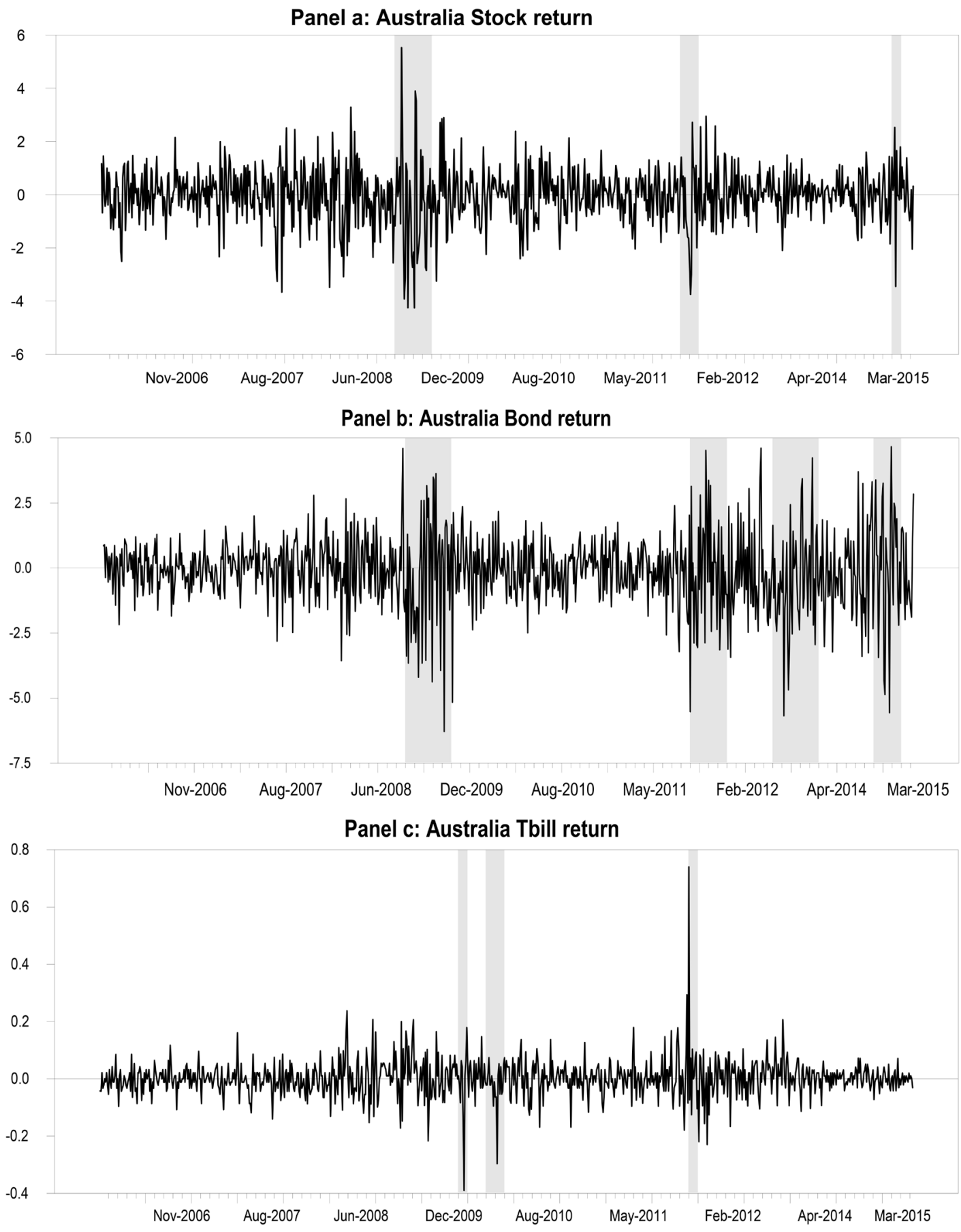

Figure 1. Time plot of daily log returns in percentage from 4 April 2006 to 20 December 2016 (x-axis representing the time dimension and y-axis representing the percentage log returns). 


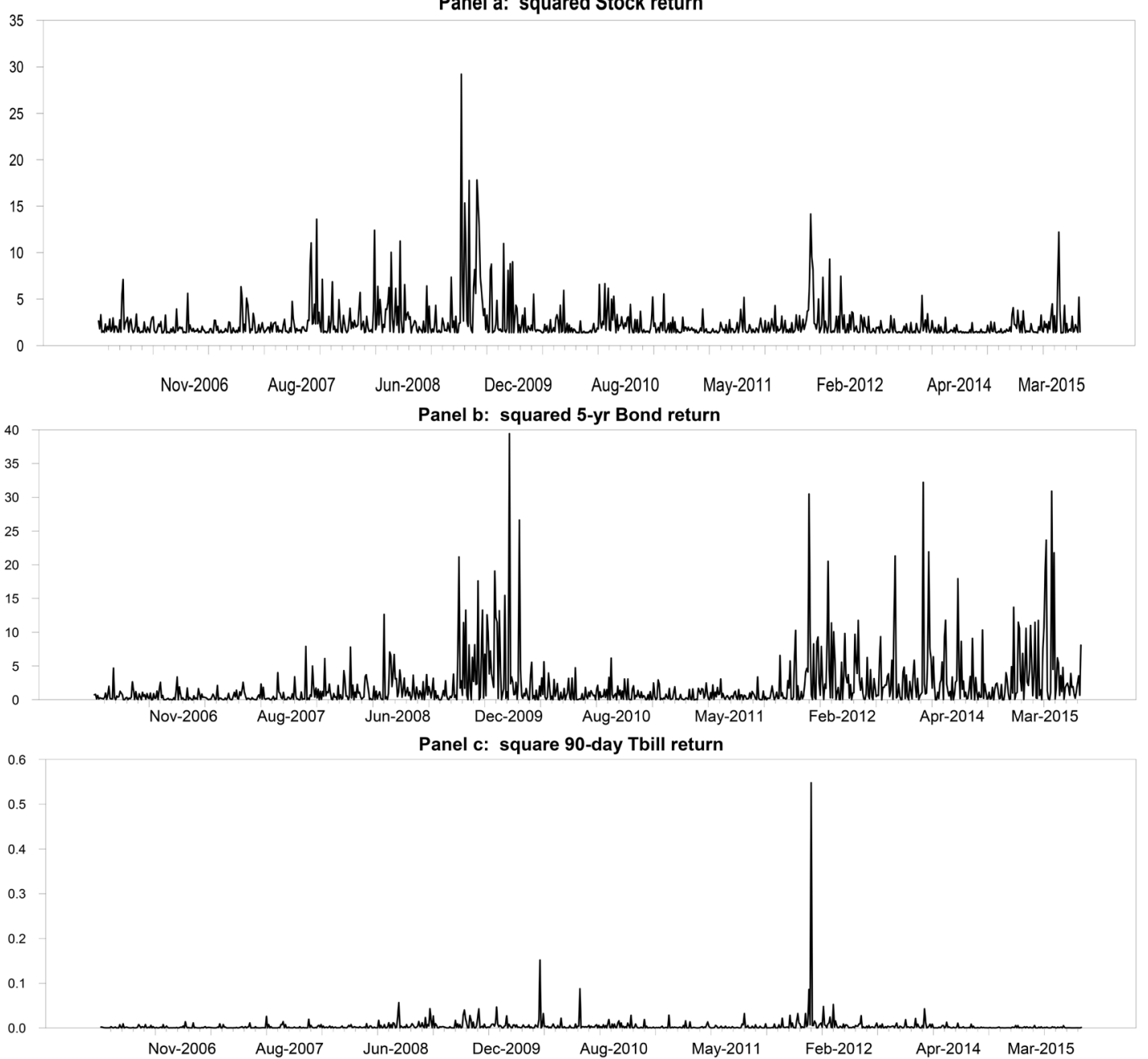

Figure 2. Time plot of the squared return series.

Table 1. Basic statistics of the return series from 4 April 2006 to 20 June 2016.

\begin{tabular}{cccc}
\hline Statistics & Stock & Bond & Tbill \\
\hline Mean (\%) & $-0.034(0.337)$ & $-0.095(0.045)$ & $0.003(0.216)$ \\
Yearly mean (\%) & -8.806 & -24.61 & 0.78 \\
Stdev (\%) & 1.062 & 1.413 & 0.065 \\
Yearly stdev (\%) & 17.09 & 22.74 & 1.05 \\
Min & -4.249 & -6.278 & -0.389 \\
Max & 5.529 & 4.667 & 0.740 \\
Skewness & $-0.203(0.0140)$ & $-0.273(0.0009)$ & $1.414(0.0000)$ \\
Excess kurtosis & $2.241(0.0000)$ & $1.816(0.0000)$ & $20.675(0.000)$ \\
LB (20) & $22.591(0.309)$ & $58.436(0.000)$ & $21.441(0.372)$ \\
LB ${ }^{2}$ (20) & $504.046(0.0000)$ & $469.484(0.0000)$ & $40.316(0.0040)$ \\
JB- $\chi^{2}$ (2) Test & $190.841(0.0000)$ & $132.348(0.0000)$ & $16020(0.0000)$ \\
Tsay Ori-F (10,865) Test (lags 4) & $4.442(0.0000)$ & $3.139(0.0006)$ & $2.619(0.0028)$ \\
McLeod and Li Test (lags 4) & $331.257(0.0000)$ & $254.087(0.0000)$ & $21.067(0.0206)$ \\
ARCH (LM) Test (lags 4) & $36.360(0.0000)$ & $16.974(0.0000)$ & $4.404(0.0000)$
\end{tabular}

Note: $p$-value is in parentheses. 
Table 2. Stationarity/non stationarity tests of the return series from 4 April 2006 to 20 June 2016.

\begin{tabular}{cccc}
\hline Return series & ADF test with lag $=5$ & PP test with lag $=5$ & KPSS test with lag $=5$ \\
\hline Stock & $-11.783^{* * *}$ & $-28.572^{* * *}$ & 0.138 \\
Bond & $-10.953^{* * *}$ & $-31.442^{* * *}$ & 0.456 \\
Tbill & $-12.277^{* * *}$ & $-30.040^{* * *}$ & 0.257
\end{tabular}

***Significant at $1 \%$ level. Note: The Null hypothesis for KPSS is stationary while ADF and PP tests the null hypothesis of non-stationarity.

\section{Estimation of the Model}

We apply AIC, BIC, and HQ criteria to select the order of the VAR of mean model. We select order 1 for VAR because among the three criteria both BIC and HQ select VAR of order 1. In the univariate case, there was overwhelming support to GARCH $(1,1)$ (Bollerslev) [3]. Considering these empirical facts, we thus proceed to fit VAR (1)-BEKK-GJR-MGARCH $(1,1)$ model. The results are reported in Section 4.1.

\subsection{Maximum Likelihood Estimation with t-Innovation}

The nonlinear maximum likelihood with t-innovation is used to estimate the parameters of the model of interest. Estimated parameters with the corresponding standard error and the $p$-value of tests are reported in Table 3.

The parameter $\left(\phi_{i j}\right) \quad(i, j=1,2,3)$ is the $(i, j)$-th element of the $(3 \times 3)$ matrix of the coefficient of the first order VAR and $\phi_{0 i}(i=1,2,3)$ is a $(3 \times 1)$ vector of intercept parameters of the mean model. The parameter $c_{i, j}$ where $i>j=1,2,3$, are the lower-triangular elements of intercept of the Variance-Covariance $(\mathrm{VCV})$ matrix; the $(3 \times 3)$ matrix of the $\mathrm{ARCH}$ and $\mathrm{GARCH}$ parameters are $\left(\alpha_{i j}\right)$ and $\left(\beta_{i j}\right)$ respectively. The $\left(\gamma_{i, j}\right)$ is the $(3 \times 3)$ matrix of leverage parameters associated with the threshold variables $\left(\eta_{i j t-1}\right)$. Similarly, $h_{i j t-1}$ is element of the symmetric variance-covariance matrix of lagged volatility and $\varepsilon_{i j t-1} \varepsilon_{i j t-1}^{\prime}$ is the squared lagged innovation. The parameter $v$ is the degrees of freedom parameter of the t-innovation density. The diagonal elements of $\alpha_{i i}, \beta_{i i}$ and $\gamma_{i i}$ are all found to be positive. Many of the parameters $\left(\alpha_{i j}\right),\left(\beta_{i j}\right),\left(\gamma_{i j}\right)$ and $\left(\phi_{i j}\right)$ for $i \neq j$ are significant in the full VAR-BEKK-GJR-MGARCH model. These results of Table 3 indicate that the leverage effects are significant with some variation. The results also demonstrate spillover effects both in the mean and the volatility models.

The shape parameter is estimated to $v=6$ (approximately). This result is based on the assumption that the trivariate $t$-distribution has common but unknown degrees of freedom. The long-run parameters $\hat{\beta}_{i i}$ 's are significant at the 0.01 level. The shot-run volatility parameters, $\hat{\alpha}_{i i}$ 's are significant between 0.01 and 0.10 levels. Many of the leverage effect coefficients are significant indicating the existence of asymmetric news effects on volatility. The value of $\mathrm{R}^{2}$ is not reported in the table because the model is highly non-linear therefore $\mathrm{R}^{2}$ is not a 
meaningful measure of goodness of fit.

The parameter stability of the model is tested by using the Nyblom score test. All of the estimated parameters, except $\phi_{10}$ and $\phi_{21}$, are found to be stable by the Nyblom test. The Nyblom joint score test statistic is found to be 8.2095 with a $p$-value of 0.28 implying that the parameters of VAR-BEKK-GJR-MGARCH are jointly stable. Parameter stability of a model is a requirement for efficient prediction of econometric models. Further, the multivariate model is tested for model adequacy using the Ljung-Box (LB) [17] statistics on the standardized residuals and squared standardized residuals of the model. Table 4 provides the Ljung-Box test results.

The LB test results fail to suggest any model inadequacy of serial dependence of the model errors.

Table 3. Maximum likelihood estimates of parameters and Nyblom score test [23] for stability from 4 April 2006 to 20 June 2016.

\begin{tabular}{|c|c|c|c|c|c|c|c|}
\hline $\begin{array}{l}\text { Parameter } \\
\text { number }\end{array}$ & Parameter & Variable & Coefficient & Std. error & $p$-value & $\begin{array}{l}\text { Nyblom } \\
\text { score }\end{array}$ & $\begin{array}{c}p \text {-value of } \\
\text { score }\end{array}$ \\
\hline 1 & $\phi_{11}$ & Stock $_{t-1}$ & $-0.059^{\star \star}$ & 0.0295 & 0.0464 & 0.241 & 0.19 \\
\hline 2 & $\phi_{12}$ & Bond $_{t-1}$ & $0.094^{\star * *}$ & 0.0282 & 0.0009 & 0.413 & 0.07 \\
\hline 3 & $\phi_{13}$ & Tbill $_{t-1}$ & $-1.956^{* * *}$ & 0.6240 & 0.0017 & 0.199 & 0.26 \\
\hline 4 & $\phi_{10}$ & Constant & $0.046^{*}$ & 0.0275 & 0.0920 & 0.047 & 0.89 \\
\hline 5 & $\phi_{21}$ & Stock $_{t-1}$ & -0.019 & 0.0263 & 0.4722 & 0.035 & 0.96 \\
\hline 6 & $\phi_{22}$ & Bond $_{t-1}$ & -0.014 & 0.0382 & 0.7152 & 0.188 & 0.28 \\
\hline 7 & $\phi_{23}$ & Tbill $_{t-1}$ & 1.120 & 0.7263 & 0.1230 & 0.486 & 0.04 \\
\hline 8 & $\phi_{20}$ & Constant & $-0.064^{\star *}$ & 0.0304 & 0.0365 & 0.062 & 0.79 \\
\hline 9 & $\phi_{31}$ & Stock $_{t-1}$ & 0.0002 & 0.0013 & 0.8887 & 0.051 & 0.86 \\
\hline 10 & $\phi_{32}$ & Bond $_{t-1}$ & 0.0019 & 0.0012 & 0.1122 & 0.301 & 0.13 \\
\hline 11 & $\phi_{33}$ & Tbill $_{t-1}$ & 0.0165 & 0.0356 & 0.6435 & 0.166 & 0.33 \\
\hline 12 & $\phi_{30}$ & Constant & 0.0007 & 0.0014 & 0.6109 & 0.084 & 0.65 \\
\hline 13 & $c_{11}$ & $C(1,1)$ & $0.202^{* * *}$ & 0.0540 & 0.0002 & 0.371 & 0.09 \\
\hline 14 & $c_{21}$ & $C(2,1)$ & -0.018 & 0.0350 & 0.6160 & 0.069 & 0.75 \\
\hline 15 & $c_{22}$ & $C(2,2)$ & 0.008 & 0.0591 & 0.8880 & 0.157 & 0.36 \\
\hline 16 & $c_{31}$ & $C(3,1)$ & -0.0002 & 0.0024 & 0.9458 & 0.074 & 0.71 \\
\hline 17 & $c_{32}$ & $C(3,2)$ & -0.0042 & 0.0031 & 0.2369 & 0.242 & 0.19 \\
\hline 18 & $c_{33}$ & $C(3,3)$ & 0.00001 & 0.0365 & 1.0000 & 0.227 & 0.22 \\
\hline 19 & $\alpha_{11}$ & $\varepsilon_{1 t-1}^{2}$ & $0.1424^{\star}$ & 0.0760 & 0.0611 & 0.438 & 0.06 \\
\hline 20 & $\alpha_{12}$ & $\varepsilon_{1 t-1} \varepsilon_{2 t-1}$ & -0.0342 & 0.0470 & 0.4663 & 0.081 & 0.67 \\
\hline 21 & $\alpha_{13}$ & $\varepsilon_{1 t-1} \varepsilon_{3 t-1}$ & -0.0017 & 0.0024 & 0.4664 & 0.160 & 0.35 \\
\hline 22 & $\alpha_{21}$ & $\varepsilon_{2 t-1} \varepsilon_{1 t-1}$ & 0.0132 & 0.0403 & 0.7436 & 0.069 & 0.75 \\
\hline
\end{tabular}




\section{Continued}

\begin{tabular}{|c|c|c|c|c|c|c|c|}
\hline 23 & $\alpha_{22}$ & $\varepsilon_{2 t-1}^{2}$ & $0.2789^{* * *}$ & 0.0368 & 0.0000 & 0.283 & 0.15 \\
\hline 24 & $\alpha_{23}$ & $\varepsilon_{2 t-1} \varepsilon_{3 t-1}$ & -0.0011 & 0.0011 & 0.3155 & 0.094 & 0.6 \\
\hline 25 & $\alpha_{31}$ & $\varepsilon_{3 t-1} \varepsilon_{t t-1}$ & 0.6959 & 0.9528 & 0.4652 & 0.087 & 0.63 \\
\hline 26 & $\alpha_{32}$ & $\varepsilon_{3 t-1} \varepsilon_{t t-1}$ & 0.4807 & 0.7197 & 0.5042 & 0.142 & 0.4 \\
\hline 27 & $\alpha_{33}$ & $\varepsilon_{3 t-1}^{2}$ & $0.1980^{* * *}$ & 0.0358 & 0.0000 & 0.084 & 0.65 \\
\hline 28 & $\beta_{11}$ & $h_{11 t-1}$ & $0.9334^{\star * *}$ & 0.0266 & 0.0000 & 0.376 & 0.08 \\
\hline 29 & $\beta_{12}$ & $h_{12 t-1}$ & -0.0165 & 0.0158 & 0.2944 & 0.034 & 0.96 \\
\hline 30 & $\beta_{13}$ & $h_{13 t-1}$ & $0.002^{*}$ & 0.0009 & 0.0771 & 0.094 & 0.6 \\
\hline 31 & $\beta_{21}$ & $h_{21 t-1}$ & 0.0010 & 0.0103 & 0.9199 & 0.047 & 0.89 \\
\hline 32 & $\beta_{22}$ & $h_{22 t-1}$ & $0.951^{* * *}$ & 0.0097 & 0.0000 & 0.359 & 0.09 \\
\hline 33 & $\beta_{23}$ & $h_{23 t-1}$ & 0.0001 & 0.0003 & 0.6932 & 0.163 & 0.34 \\
\hline 34 & $\beta_{31}$ & $h_{31 t-1}$ & -0.286 & 0.2995 & 0.3406 & 0.056 & 0.83 \\
\hline 35 & $\beta_{32}$ & $h_{32 t-1}$ & $-0.441^{*}$ & 0.2360 & 0.0619 & 0.150 & 0.38 \\
\hline 36 & $\beta_{33}$ & $h_{33 t-1}$ & $0.970^{\star * *}$ & 0.0123 & 0.0000 & 0.203 & 0.25 \\
\hline 37 & $\gamma_{11}$ & $\eta_{11 t-1}$ & $-0.361^{\star * \star}$ & 0.0559 & 0.0000 & 0.175 & 0.31 \\
\hline 38 & $\gamma_{12}$ & $\eta_{12 t-1}$ & $-0.151^{\star * *}$ & 0.0549 & 0.0059 & 0.149 & 0.38 \\
\hline 39 & $\gamma_{13}$ & $\eta_{13 t-1}$ & $0.0095^{\star * *}$ & 0.0027 & 0.0005 & 0.204 & 0.25 \\
\hline 40 & $\gamma_{21}$ & $\eta_{21 t-1}$ & -0.0201 & 0.0593 & 0.7343 & 0.271 & 0.16 \\
\hline 41 & $\gamma_{22}$ & $\eta_{22 t-1}$ & $0.1743^{* * *}$ & 0.0460 & 0.0002 & 0.351 & 0.1 \\
\hline 42 & $\gamma_{23}$ & $\eta_{23 t-1}$ & -0.0016 & 0.0013 & 0.2237 & 0.120 & 0.48 \\
\hline 43 & $\gamma_{31}$ & $\eta_{31 t-1}$ & -0.2331 & 1.2646 & 0.8538 & 0.136 & 0.42 \\
\hline 44 & $\gamma_{32}$ & $\eta_{32 t-1}$ & 1.0941 & 1.1152 & 0.3266 & 0.129 & 0.44 \\
\hline 45 & $\gamma_{32}$ & $\eta_{33 t-1}$ & 0.0194 & 0.0786 & 0.8055 & 0.160 & 0.35 \\
\hline 46 & v & Shape & $5.8344^{* * *}$ & 0.6185 & 0.0000 & 0.096 & 0.58 \\
\hline
\end{tabular}

Note: ${ }^{* * *} 1 \%,{ }^{* *} 5 \%$, and ${ }^{*} 10 \%$ level of significance.

Table 4. Univariate and multivariate Ljung-Box test for model adequacy from 4 April 2006 to 20 June 2016.

\begin{tabular}{ccccc}
\hline Ljung-Box statistic & Stock market & Bond market & Money market & Multivariate model \\
\hline LB-Q (10) & $14.012(0.172)$ & $7.357(0.691)$ & $7.983(0.631)$ & $97.26806(0.282)$ \\
LB-Q ${ }^{2}(10)$ & $11.527(0.318)$ & $8.836(0.548)$ & $11.228(0.340)$ & $95.97079(0.314)$ \\
& & & & \\
LB-Q (20) & $21.746(0.354)$ & $26.784(0.141)$ & $17.986(0.588)$ & $197.09522(0.182)$ \\
LB-Q ${ }^{2}(20)$ & $20.514(0.426)$ & $24.187(0.234)$ & $20.407(0.433)$ & $165.92558(0.766)$ \\
\hline
\end{tabular}

Note: $p$-value of the LB-test is in parentheses.

\subsection{Spillover Effects of Stock, Bond, and Tbill}

In this section we report the spillover and leverage effects of return and volatilities of returns. Based on the MLE estimates of the VAR-BEKK-GJR-MGARCH 
model parameters we conduct the spillovers effect of returns, volatility and leverage effects. The tests are based on Wald Chi-square statistic.

The test results in Table 5(a) suggests that there are significant return spillovers running from Bond and Tbill to stock returns in Australia's domestic assets markets. Also there are significant spillovers from Stock and Tbill to bond return. However, spillovers from stock and bond jointly are statistically insignificant in explaining the Tbill. The reason could be that the Tbill is short term security.

The test results of Table 5(b) suggest significant volatility spillovers from Bond and Tbill to stock. The test result also suggests significant volatility spillovers from stock and bond is statistically significant in explaining the volatilities in Tbill. However, the volatility does not jointly spillovers from stock and Tbill to bond. The reason for this could be news impact. These observations suggest that the Australia's domestic asset markets are interlinked and transmit return and volatility spillovers across domestic asset markets. This information is useful in planning for future investment decisions both by individuals and financial institutions to minimize risk

Table 5. (a) Return spillover test from 4 April 2006 to 20 June 2016; (b) Volatility spillover test from 4 April 2006 to 20 June 2016; (c) Tests for leverage effect daily data from 4 April 2006 to 20 June 2016.

(a)

\begin{tabular}{|c|c|c|}
\hline \multicolumn{2}{|c|}{ Return spillover } & \multirow{2}{*}{ Chi-square } \\
\hline From & To & \\
\hline Bond and Tbill & Stock & $51.379(0.000)$ \\
\hline Stock and Tbill & Bond & $3.292(0.000)$ \\
\hline Stock and bond & Tbill & $2.534(0.193)$ \\
\hline
\end{tabular}

Note: $p$-value is in parentheses.

(b)

\begin{tabular}{|c|c|c|}
\hline \multicolumn{2}{|c|}{ Volatility spillover } & \multirow{2}{*}{ Chi-square } \\
\hline From & To & \\
\hline Bond and Tbill & Stock & $11.708(0.000)$ \\
\hline Stock and Tbill & Bond & $4.960(0.291)$ \\
\hline Stock and Bond & Tbill & $7728.681(0.000)$ \\
\hline
\end{tabular}

Note: $p$-value is in parentheses.

(c)

\begin{tabular}{cccc}
\hline Asset & Effects of own shock and shocks of the other assets & Test statistic with $p$-value \\
\hline Stock & $H_{0}: \gamma_{11}=\lambda_{12}=\gamma_{13}=0$ & $H_{1}: \gamma_{11} \neq \lambda_{12} \neq \gamma_{13} \neq 0$ & $\chi^{2}=61.6435(0.000)$ \\
Bond & $H_{0}: \gamma_{21}=\lambda_{22}=\gamma_{23}=0$ & $H_{1}: \gamma_{21} \neq \lambda_{22} \neq \gamma_{23} \neq 0$ & $\chi^{2}=16.734(0.000)$ \\
Tbill & $H_{0}: \gamma_{31}=\lambda_{32}=\gamma_{33}=0$ & $H_{1}: \gamma_{31} \neq \lambda_{32} \neq \gamma_{33} \neq 0$ & $\chi^{2}=2.651(0.449)$ \\
\hline
\end{tabular}

Note: $p$-value of the test is in parentheses. 
Next we test the leverage in volatility transmission across domestic asset markets. In the context of multivariate asset market trade dynamics, it is important for asset management to know how the "news" spread over to other assets and increase the risk of holding risky assets. Since the negative news have the greater influence on future volatility than do the gains, we therefore, test for the leverage effects of the asset's own shock and shocks due to the other assets in the multiple financial markets. This has been empirically investigated by testing the leverage parameters across assets jointly by utilizing the Wald Chi-square test. The test results of the leverage parameters $\gamma_{i j}$ are provided in Table 5(c). Table 5(c) shows that there is a significant leverage effects transmitting from stock's own shock, and the shocks due to the bond and Tbill markets to the stock market. Further, significant asymmetric leverage effects transmitting from bond's own shock, and the shocks due to the stock and Tbill markets to the bond markets jointly. However, no significant leverage effects transmit jointly from Tbill's own shock, and the shocks are due to the stock and bond markets to the Tbill market. These observations are useful, for the Australia's domestic investors, for optimal asset al. location strategies for future investment decision.

\subsection{Pattern of Change in Predicted Volatility and Correlations}

The estimated model satisfies most of the desirable properties, namely model adequacy, parameter consistency, volatility clustering and leverage effects. As mentioned before, a good forecast model must capture all stylized facts of the data. In this regard, our VAR-BEKK-GJR-MGARCH ( $t$ ) model can be used for modelling and predicting volatility and correlation of return volatilities. The graph below displays time plot of the predicted time varying volatility and correlations.

Figure 3 shows both in-sample and out-of-sample predicted volatilities and correlations of volatilities between assets. The main diagonal of Figure 3 displays the predicted volatility and the off-diagonal graphs display the predicted volatilities. The predicted volatilities of bond, stock and Tbill exhibit changes the pattern of movement over time. The out-of-sample volatility prediction of each of the security is tranquil. This is the recovery of the GFC. The prediction of correlation of volatility between stock and bond, and Tbill and stock are both positive in the 100-step-ahead prediction. But a mix of both negative and positive is during in-sample prediction. However, both the in-sample and out of sample prediction of correlation of volatility between Tbill and bond are negative. This carries useful information about the asset markets interaction and trade-off, which is consistent with our previous findings. The volatility prediction is monotonically decreasing in all cases after 2011. The out-of-sample prediction is tranquil for Tbill but the stock and bond price volatility continues to fall. The overall Predicted bond return is more volatile than the predicted stock returns during 2011. There were some tranquil periods both in bond and Tbill volatility predictions during the mid-2007 and a severe peak in all of the securities' volatility during 2011-2012. All those are the European financial crisis periods. 

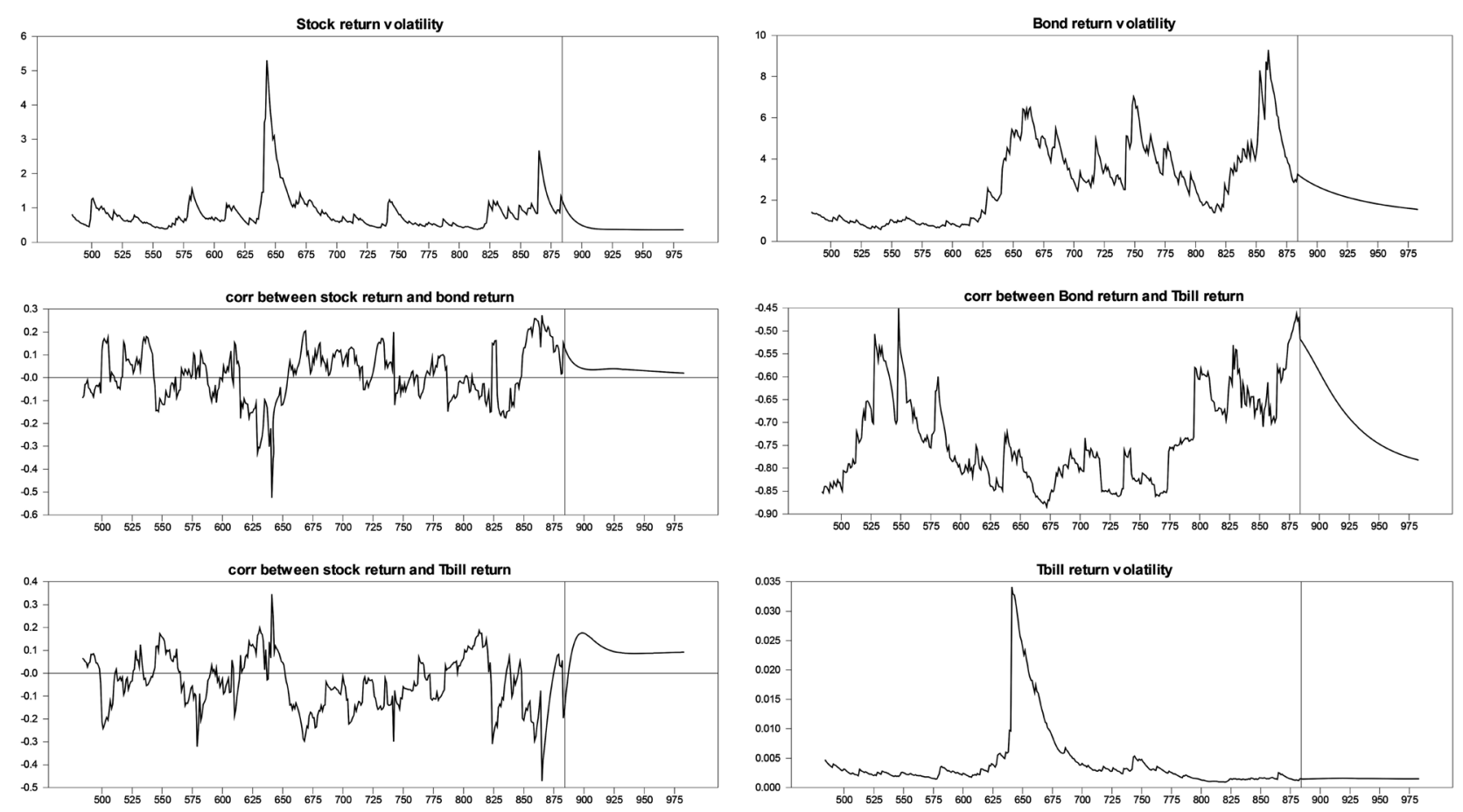

Figure 3. Predicted volatility and correlations of stock, bond, and Tbill.

\section{Conclusion}

In this paper we investigate the impact of news on volatility in the multiple asset markets using VAR-BEKK-GJR-MGARCH model. Although this model contains a large number of parameters, its statistical second order moment property holds. This model is capable to capture both asymmetric error distributions (measuring news effects) and "volatility leverage". To our knowledge, application of the simultaneous occurrence of asymmetry and leverage effects on volatility in the Australia's domestic financial markets is the first. This paper contributes to both methodology and real application within the multivariate financial volatility modelling context. The new modelling strategy of this paper provides important additional information about the sources and linkages among the domestic asset markets of Australia. The results of this paper show that the Australian's domestic asset markets are interdependent in general. Significant volatility spillovers from stock market to the bond and to money markets simultaneously due to common news information which is supported by the Wald chi-square tests. Time plot of the daily log returns highlights that the domestic bond market is affected most by the global financial crises (GFC), while Tbill is least affected as Tbill is more liquid than the bond market. We also find significant volatility leverage effects from bond and money markets to the stock market and from stock and money markets to the bond market. However, no significant volatility leverage effects are found from stock and bond markets to Tbill. The correlation between Tbill and bond returns volatility is negative, indicating that there is a trade-off between bond and Tbill. This information is useful and vital 
for asset management and portfolio diversification strategies. Stock and bond volatility correlation is a mix of both positive and negative but with that some noticeable negative correlation is reported between these two assets during 2011 and 2012. Volatility correlations between asset returns are important for policy makers' asset allocation through diversification during trading under uncertainty. In general, the model adequately fits the data by the LB and Nyblom tests. Significant simultaneous presence of "news" and leverage effects and volatility spillovers determine the sources of volatility transmission across domestic asset markets of Australia. The short and long run volatility parameters are found to be significant with some reservation. The dynamic interactions affect investors' expectation of trading securities in the Australia's domestic financial markets simultaneously. The approach of this paper can be extended to investigate spatial dependence of volatility \& correlation spillovers across countries for modelling and predicting returns and volatilities simultaneously in the international financial markets for global financial investment policy decision purposes.

\section{Conflicts of Interest}

The authors declare no conflicts of interest regarding the publication of this paper.

\section{References}

[1] Black, F. (1976) Studies of Stock Price Volatility Changes. Proceedings of the 1976 Meeting of the Business and Economic Statistics, American Statistical Association. Washington DC, 1976, 177-181.

[2] Engle, R.F. (1982) Autoregressive Conditional Heteroscedasticity with Estimates of the Variance of United Kingdom Inflation. Econometrica, 50, 987-1007. https://doi.org/10.2307/1912773

[3] Bollerslev, T. (1986) Generalized Autoregressive Conditional Hetroskedasticity. Journal of Econometrics, 31, 307-327. https://doi.org/10.1016/0304-4076(86)90063-1

[4] Nelson, D.B. (1991) Conditional Heteroskedasticity in Asset Returns: A New Approach. Econometrica, 59, 347-370. https://doi.org/10.2307/2938260

[5] Engle, R.F. and Ng, V.K. (1993) Measuring and Testing the Impact of News on Volatility. The Journal of Finance, 48, 1749-1778. https://doi.org/10.1111/j.1540-6261.1993.tb05127.x

[6] Glosten, L.R., Jagannathan, R. and Rukle, D.E. (1993) On the Relation between the Expected Value and the Volatility of the Nominal Excess Return on Stocks. The Journal of Finance, 48, 1779-1801. https://doi.org/10.1111/j.1540-6261.1993.tb05128.x

[7] Engle, R.F. and Granger, C.W.J. (1987) Co-Integration and Error Correction: Representation, Estimation, and Testing. Econometrica, 55, 251-276. https://doi.org/10.2307/1913236

[8] Bollerslev, T., Engle, R.F. and Wooldridge, J.M. (1988) A Capital Asset Pricing Model with Time-Varying Covariances. Journal of Political Economy, 96, 116-131. https://doi.org/10.1086/261527 
[9] Bera, C.M. (1980) Efficient Tests for Normality, Homoscedasticity and Serial Independence of Regression Residuals. Economics Letters, 6, 255-259. https://doi.org/10.1016/0165-1765(80)90024-5

[10] Enders, W. (2014) Applied Time Series. John Wiley and Sons, Hoboken.

[11] Baba, Y.S. (1992) The demand for M1 in USA, 1960-1988. Review of Economic Statistics, 59, 25-61. https://doi.org/10.2307/2297924

[12] Engle, R.F. and Kroner, K.F. (1995) Multivariate Simultaneous Generalized ARCH. Econometric Theory, 11, 122-150. https://doi.org/10.1017/S0266466600009063

[13] Ling, S. and McAleer, M. (2003) On Adaptive Estimation in Nonstationary ARMA Models with GARCH Errors. The Annals of Statistics, 31, 642-674. https://doi.org/10.1214/aos/1051027884

[14] Engle, R. (2002) Dynamic Conditional Correlation: A Simple Class of Multivariate Generalized Autoregressive Conditional Heteroskedasticity Models. Journal of Business \& Economic statistics, 20, 339-350. https://doi.org/10.1198/073500102288618487

[15] Tse, Y.K. and Tsui, A.K.C. (2012) A Multivariate Generalized Autoregressive Conditional Heteroscedasticity Model with Time-Varying Correlations. Journal of Business \& Economic Statistics, 20, 351-362. https://doi.org/10.1198/073500102288618496

[16] Zakoian, J.-M. (1994) Threshold Heteroskedastic Models. Journal of Economic Dynamics and Control, 18, 931-955. https://doi.org/10.1016/0165-1889(94)90039-6

[17] Ljung, G.M. and Box, G.E. (1978) On a Measure of Lack of Fit in Time Series Models. Biometrika, 65, 297-303. https://doi.org/10.1093/biomet/65.2.297

[18] Tsay, R.S. (1986) Time Series Model Specification in the Presence of Outliers. Journal of the American Statistical Association, 81, 132-141. https://doi.org/10.1080/01621459.1986.10478250

[19] McLeod, A.I. and Li, W.K. (1983) Diagnostic Checking ARMA Time Series Models Using Squared Residual Autocorrelations. Journal of Time Series Analysis, 4, 269-273. https://doi.org/10.1111/j.1467-9892.1983.tb00373.x

[20] Jarque, C.M. and Bera, A.K. (1987) A Test for Normality of Observations and Regression Residuals. International Statistical Review, 55, 163-172. https://doi.org/10.2307/1403192

[21] Fuller, D.D. (1981) Likelihood Ratio Statistics for Autoregressive Time Series with a Unit Root. Econometrica, 49, 1057-1072. https://doi.org/10.2307/1912517

[22] Perron, P.C. (1988) Testing for a Unit Root in Time Series Regression. Biometrika, 75, 335-346. https://doi.org/10.1093/biomet/75.2.335

[23] Nyblom, J. (1989) Testing for the Constancy of Parameters over Time. Journal of the American Statistical Association, 84, 223-230. https://doi.org/10.1080/01621459.1989.10478759 